\title{
Advancing the ACM Agenda
}

\section{ACM is a fairly compact organization, looking only at its modest but spirited staff, now led by the energetic team of CEO Bobby Schnabel and COO Pat Ryan. For the sake of saving}

space, I have not tried to list all the other wonderful staffers who tend to the machinery of ACM's operation and support the much larger volunteer structure that makes ACM what it is today. On the record, we have a first-rate team of full-time talent keeping ACM humming. But, alone, the staffers do not and could not make ACM the diverse and multifaceted organization it is. The volunteers, many of whom have served in multiple roles over decades, provide ACM with the intellectual and operational muscle power it needs to carry out myriad activities in support of computer science professionals and practitioners around the world. It is interesting to note that many of our dedicated ACM volunteers started with a single, focused commitment to, say, a program committee or a particular publication and over time and further engagement have become some of the most effective leaders of our association. Indeed, ACM volunteers come to value the impact they can make serving our community.

Despite the fact I have been a member of ACM since 1967, I am still discovering new things that ACM is involved in, and this after serving as president and now past-president for the past 3.5 years! The diversity of activity is well illustrated in ACM's Web pages but I confess I do not visit them enough to stay on top of everything. My New Year's resolution is going to be to visit the pages at least once a week to see what is going on. ACM is looking for new ways to draw attention to its agenda and to opportunities for members and beneficiaries of ACM's work to discover and participate in the many volunteer opportunities that abound in our online and offline, computer-driven world. Just scanning the special interest group activities highlights the remarkable range of interests we serve. With the addition of the regional councils and chapters in India, China, and Europe, and elsewhere, ACM's footprint and scope of opportunity has increased notably.

This brings me to the first point of this column: diversity is key to ACM's ability to prosecute its agenda and to deliver benefits to members and practitioners around the world. The second point is that volunteers are absolutely essential to achieving the many goals ACM's volunteer leadership has adopted over the years. We need to expand outreach to underrepresented populations of computer professionals and educators and to the general public. We would benefit from many more volunteers and members drawn from non-U.S. populations, women, and other underrepresented minority groups, all of whom bring important perspectives and energy to ACM's mission. Just thinking about accessibility of computer-based systems reminds me how important it is to engage with users who would benefit from various assistive technologies and methods. We have a SIG focused on this community (SIGACCESS), but we also need members of these communities to feel and be welcome and supported in all our SIGs and our activities. We need to make ACM itself and its functions and activities as accessible as possible.

Diversity does not stop with accessibility. If we are to be a successful global organization, diversity on all fronts must be a global ambition. That means we must work with and empower our regional councils to help draw attention to the volunteer opportunities available within the ACM framework and to the valuable products and services that are the output of ACM's efforts. It means we need to encourage and spur efforts to bring women and minority groups more fully into the ACM family. And that brings me to another point about diversity.

We are entering into our biannual election process for leadership in ACM's volunteer component. The able, top-leadership team of Alex Wolf, Vicki Hanson, and Erik Altman will have completed their statutory twoyear terms by the end of June 2016 and it is time to elect new officers. As the electorate, you have both the opportunity and the obligation to give careful thought to your choices for leadership. I chair the nominations committee as past president and I have also sought to impress on the committee the importance of diversity in our recommendations for candidates for volunteer leadership positions. It is my hope we can collectively put ACM on a track toward greater diversity in all dimensions of its activities, including our SIGs and other special interest groups, such as ACM-W.

We are already actively pursuing these goals and your election choices represent one way to spur the organization toward greater success in volunteer diversity in the years ahead.

Vinton G. Cerf is vice president and Chief Internet Evangelist at Google. He served as ACM president from 2012-2014.

Copyright held by author. 